\title{
山口県棯小野地域の閃長岩質岩石 (I)*
}

\section{Syenitic Rocks of the Utsugiono District, Yamaguchi \\ Prefecture (I)}

$$
\text { 村上允 英 (Nobuhide Murakami)** }
$$

Abstract: Syenitic and alkali-granitic rocks are dike-like masses in the granitic rocks of the Utsugiono district. They are divided in to the following six types.

1. Leucocratic and garnet-syenitic rocks.

2. Pyroxene-hornblende- and hornblende-syenitic rocks

3. Epidote-syenitic rocks.

4. Potash-syenitic rocks.

5. Porphyritic syenitic rocks.

6. Syenitic aplite

Gradational relation can be found between syenitic rocks, which are very crushed and recrystallized, marginal alkali-granitic rocks, and outer granites. When alkali-granitic rocks contact with pegmatitic veins, there can not be found any mutual intrusive relation, but plagioclase crystals in pegmatite are albitized and in latter rocks quartz often decreases.

From these facts, it is concluded that shear zones in granitic rocks have been transformed to be syenitic by the effect of metasomatic reaction with alkali-solution and metamorphic differentiation in granitic rocks. The original solution might have been albitic and followed to the arrow direction in geological map, being gradually potassic by the reaction with granitic rocks, as shown by the relation between rock types, modal compositions, minerals, and the distribution of syenitic rocks.

The peculiar syenitic rocks in the Setouchi region might equally be interpreted as of similar metasomatic origin.

\section{Iはじめに}

瀬户内海地域の花崗岩中に洼異な閔長岩質岩石が点々と分布している。これらの岩 石について注古くより注目されていたが，一部の岩石記載を除いてはその地質学的性状・

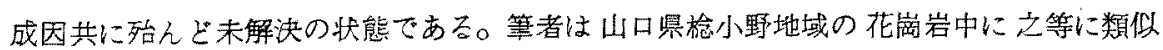
の岩体を見出した。現在なミ未解決の問題もあるが，一応その興味ある地質学的，岩石学 的性質について報告する事とする。

*1955年 12月 日本地質学会西日本交部例会発表原稿に一部加筆補正

** 山口大学文理学部地学教定 
Fig. 1. Geological Map of the Utsugiono District.

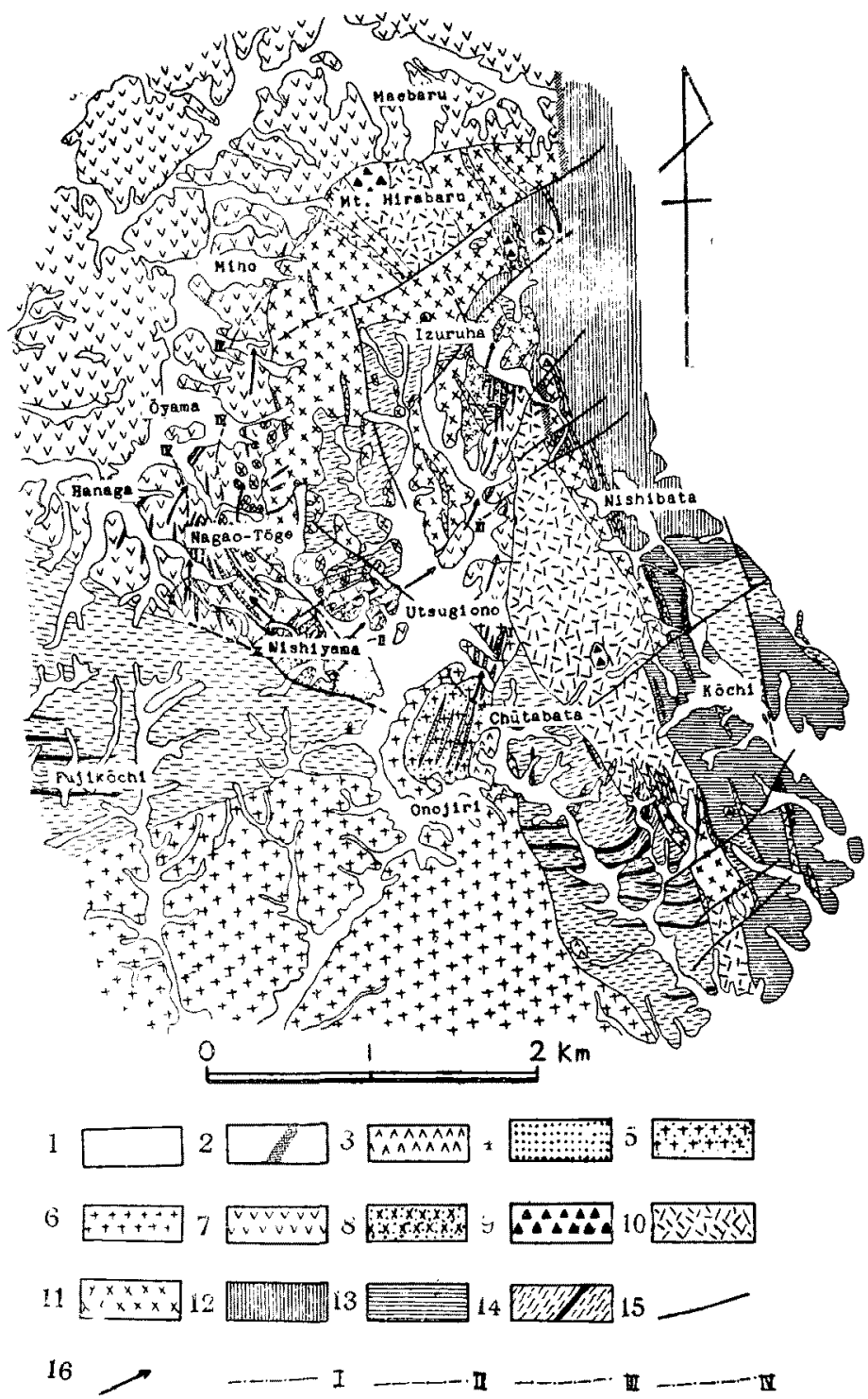

\section{II 地 貿 の 概 略}

当地域は吉部成岩体の南端にあたる。筆者いがかつてその概要を述へた椂に，分布す

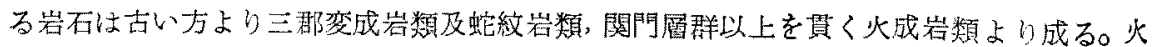

1) 村山允英 $(1954)$; 山日大学理学会誌 5,77 
成岩類は次の3時期のものに分けられる。

1）出葉酸性岩類 花南閃緑岩，半花崗岩，斜長斑岩より成り，NNW〜NW 万向の破

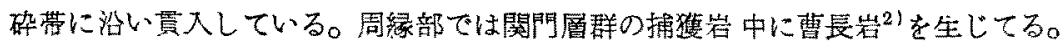

2) 玢岩 出葉酸性岩類变貫 (岩株, 岩服状岩体。

3) 花岗岩類 上記諸岩体さ貫き主にNE 万向の破碎带に関保している。次の栚な岩 型が認められ，それらの組成銥物量比は Fig. 2, Table 1 に示寸通りである。

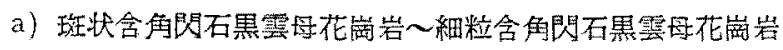

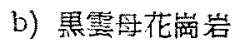

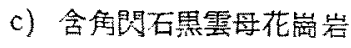

d) 粗粒黒雲然花崗岩

Fig. 2. Variation in modal compositicn of granitic rccks.

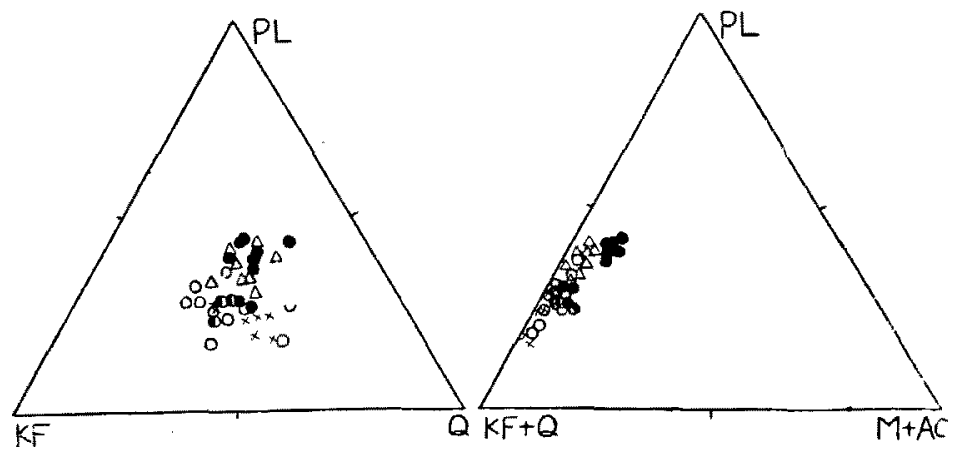

PL; plagioclase, KF; potash-feldspar, Q; quartz, M; mafic minerals, Ac; accessory minerals. solid circle; hornblende-bearing biotite-granite, semisolid circle; Granite, near contact to granodiorite xenolith, triangle; biotite-granite. open circle; coarse-grained biotite-granite, Crosses; lelacocratic granites in other localities of syenitic rocks in South-western Japan.

Fig. 1. Geological Map of the Utsugiono District.

1 ; Alluvium, 2; Quartz-porphyry, 3; Hornblende-biotite-granite-porphyry, 4 ; Syenitic rocks and alkali-granitic rocks, 5; Coarse-grained biotitegranite, 6; Biotite-granite, 7; Hornblende-bearing biotite-granite, 8; Porphyritic granite, 9; Porphyrite, 10; Plagiophyre, 11; Granodiorite, 12; Shimonoseki sub-group, 13; Wakino sub-group, 14; Sangun crystalline schists and serpentinites, 15; Fault, 16; Flow direction of alkali-solution, I; Boundary line between leucocratic syenitic rocks and hornblendesyenitic rocks, II; Boundary line between soda-rich pyroxene-hornblendesyenitic rocks and pyroxene-hornblende-syenitic rocks or epidote-syenitic rocks (western district), III; Boundary line between hornblende-syenitic rocks and epidote-syenitic rocks, IV; Boundary line between potashsyenitic rocks and epidote-syenitic rocks.

1) 村上允英(1955)；岩鉣 39，68 
何れもアブライト、ベグマタイを件い，又珪長岩，煌斑岩岩脈に貫かれる。なおb

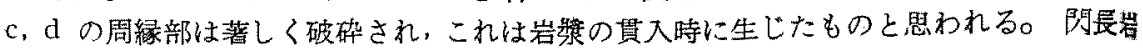

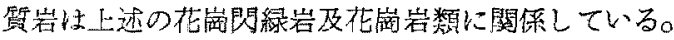

Table 1. Average Modal Composition of Granitic Rocks.

\begin{tabular}{|c|c|c|c|c|c|c|}
\hline Minerals & $\begin{array}{l}\text { Porphy- } \\
\text { ritic } \\
\text { granite }\end{array}$ & $\begin{array}{l}\text { Fine- } \\
\text { grained } \\
\text { granite }\end{array}$ & $\begin{array}{l}\text { Biotite- } \\
\text { granite }\end{array}$ & $\begin{array}{l}\text { Hornble- } \\
\text { nde } \\
\text { bearing } \\
\text { biotite- } \\
\text { granite }\end{array}$ & $\begin{array}{l}\text { Granite, } \\
\text { near contact } \\
\text { to granodio- } \\
\text { rite xenolith }\end{array}$ & $\begin{array}{c}\text { Coarse- } \\
\text { grained } \\
\text { biotite- } \\
\text { granite }\end{array}$ \\
\hline $\begin{array}{l}\text { Hornblends } \\
\text { Biotite }\end{array}$ & $\begin{array}{l}1.7 \\
7.9\end{array}$ & $\begin{array}{l}0.3 \\
6.1\end{array}$ & 3.8 & $\begin{array}{l}0.7 \\
5.9\end{array}$ & $\begin{array}{l}0.4 \\
3.2\end{array}$ & 1.8 \\
\hline $\begin{array}{l}\text { Plagio- } \\
\text { clase }\end{array}$ & 43.5 & 33.7 & 35.9 & 35.9 & 26.7 & 26.0 \\
\hline $\begin{array}{l}\text { Potash- } \\
\text { feldspar }\end{array}$ & 23.8 & 32.5 & 28.2 & 26.8 & 37.0 & 38.3 \\
\hline Quartz & 22.9 & 27.3 & 31.9 & 30.5 & 32.7 & 33.8 \\
\hline Accessory & 0.2 & 0.2 & 0.2 & 0.2 & 0.1 & 0.1 \\
\hline
\end{tabular}

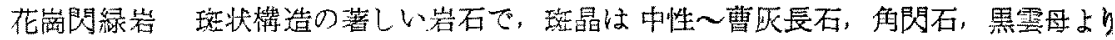

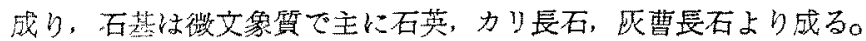

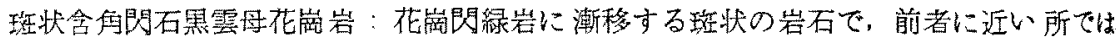

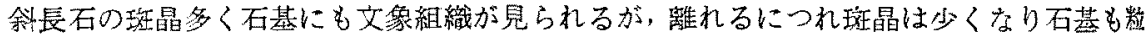
状化してくる。玟晶䣄展石の核部は中性〜曹欧長石で著しく污濁しているが，周緑部は此

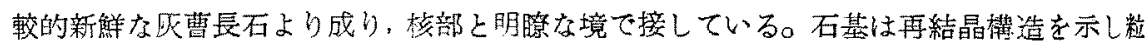

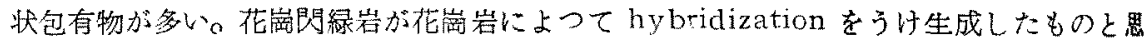
われる。

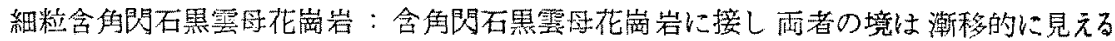
事も多いが，前者法得により混成化をうけている。その性状より $\mathrm{K}_{2} \mathrm{O}$ の附加を伊う琉

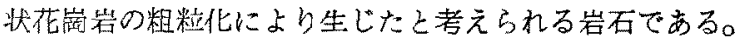

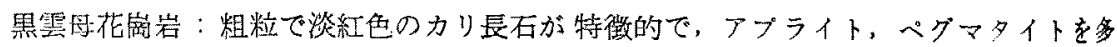
く体う。南部に分布が広い。斜長石は An 13〜40 の成分を有する。

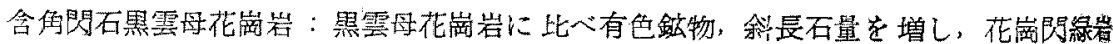
体に近い所程多く含まれる。但し花嵐閃緑岩捕獾岩に近接する所では局部的にカリ莀石， 石宾量の多い事がある。斜長石には可成り石灰質（An40～60) の核部が㞗マあり，又同

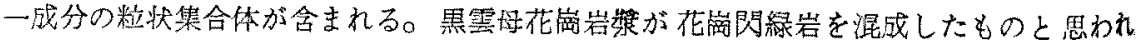
\$o

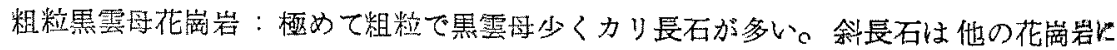

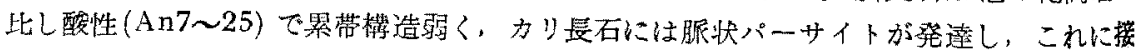
する斜長石には著しい sodic rim が生じている。アブライト服が多い。

\section{II 分布及産 状}

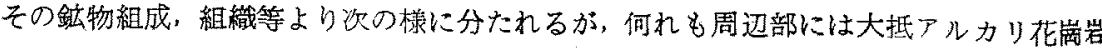




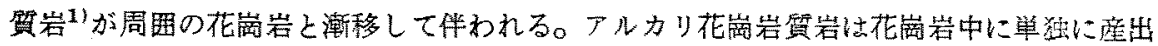
する事是ある。

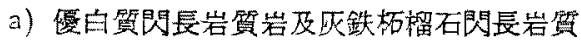
岩

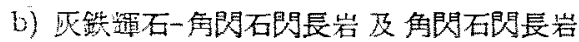

\section{貿岩}

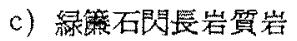

d) 力閃長岩貿岩

e) 玨状成長岩筫岩

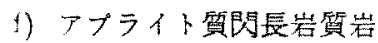

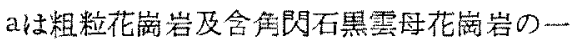

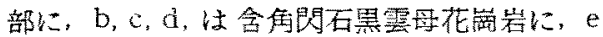

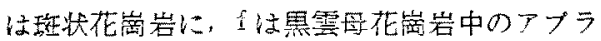
イト筫花涌岩に夫々伴われる。

これらの岩体は花崗岩体の周縁部，特に既述

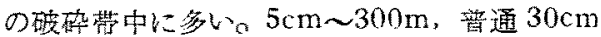
～5m 程の胍状体 (Fig．3) て時に直交する枝 状部を有する專当すり，稀にポケット状の事が

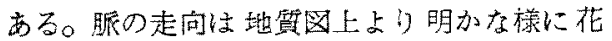

Fig. 3. Syenitic rock and alkaligranitic rock in dike-like form.

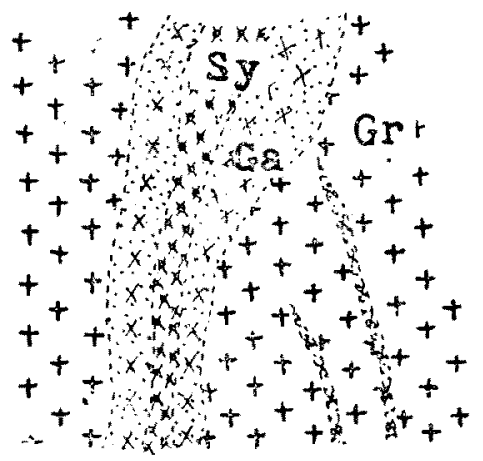

\section{l $m$}

Gr; hornblende-bearing biotitegranite, Sy; syenitic rock, Ga; alkali-granitic rock.

Tuble 2. Modal Composition of Typical Syenitic Rocks.

\begin{tabular}{|c|c|c|c|c|c|c|c|}
\hline Minerals & $\begin{array}{l}\text { Teucocra } \\
\text { tic syeni- } \\
\text { tic } \\
\text { rock }\end{array}$ & $\begin{array}{l}\text { Garnet- } \\
\text { syenitic } \\
\text { rock }\end{array}$ & $\begin{array}{l}\text { Hornble- } \\
\text { nde-pyr- } \\
\text { oxene- } \\
\text { syenitic } \\
\text { rock }\end{array}$ & $\begin{array}{l}\text { Hornble- } \\
\text { nde-sye- } \\
\text { nitic } \\
\text { rock }\end{array}$ & $\begin{array}{l}\text { Epidote- } \\
\text { syenitic } \\
\text { rock }\end{array}$ & $\begin{array}{l}\text { Potash- } \\
\text { syenitic } \\
\text { rock }\end{array}$ & $\begin{array}{l}\text { Syenitic } \\
\text { aplite }\end{array}$ \\
\hline Pyroxene & & & 10.3 & & & & \\
\hline $\begin{array}{l}\text { Hornble- } \\
\text { nde }\end{array}$ & & & 1.0 & 11.5 & & & \\
\hline $\begin{array}{l}\text { Epidote } \\
\text { Garnet }\end{array}$ & & 14.3 & 0.2 & $\begin{array}{l}0.3 \\
0.8\end{array}$ & 15.8 & 10.2 & \\
\hline $\begin{array}{l}\text { Plagio- } \\
\text { clase }\end{array}$ & 83.5 & 69.9 & 84.7 & 79.1 & 40.5 & 8.3 & 99.9 \\
\hline $\begin{array}{l}\text { Potash- } \\
\text { feldspat }\end{array}$ & & & & 6.6 & $36 \cdot 7$ & 80.3 & \\
\hline Quartz & 16.2 & 15.5 & 0.8 & 0.0 & 6.4 & 0.1 & \\
\hline Others & 0.3 & 0.3 & 4.0 & 1.8 & 0.5 & 1.2 & 0.1 \\
\hline
\end{tabular}

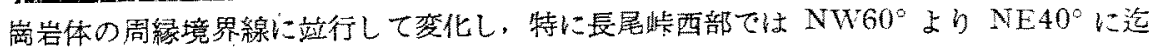
変化している。同一走向の破䂺带・節理・岩眽類も多いが，NE50〜70 の王長岩・鼻斑 岩岩脈に貫かれる。

\section{III鏡下の性 監}

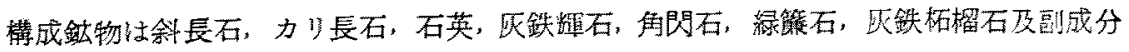

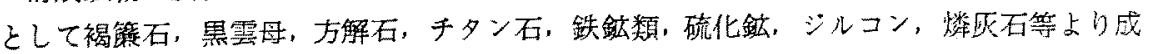

1) アルカリ交代をうけた化嵐岩が直接する事もある。 
る。組織の上では破研及再結晶の著しい事が特致で, 波動消光, 屈曲, 破砕, 粒状化がと の鍍物にも新められる。

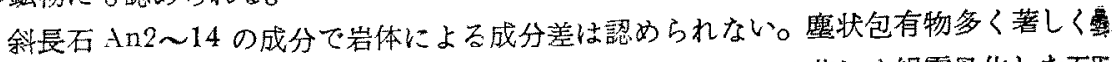
り、特に有色鉣物の多い岩石に著しい。アルカリ花崗岩質岩では著しく絹雲母化した石庅 質核部の見られる事がある。次の橵な座状のすのがある。

(1) 大型平自形晶，テルバイト双晶がが発達する。

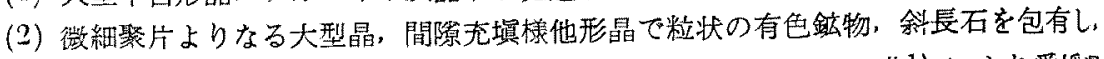
アルカリ花崖岩質岩には稀である。同一性状のものは杉健一，久綱正典”により愛媛累 岩城島のエキリン閃長岩中に見出されている。世界各地の keratophyre 類に含まれる chequer-albite 2) に䓡似したものと思われる。

(3) mortar texture 它成す糧状集合体

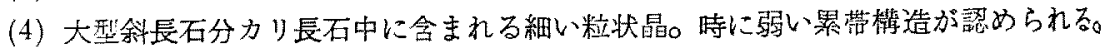

(5)破砕組織の著しい所に㞗々ある細い脈状体。緑籍石等の細脈に屡々伴われる。

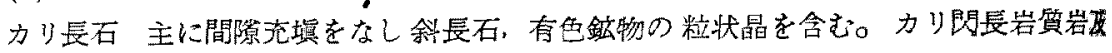

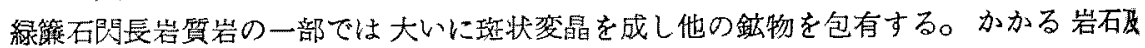

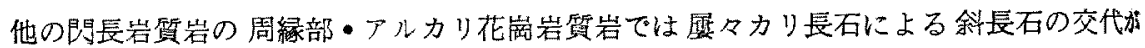
諗められる。交代は辟開か緑に沿い，或いは不規則に行われ遂に以前の外形のまま全体济 交代される。微斜長石構造は認められないが光学性上り微斜長石に属する事が分る。

石英他の鉱物を交代或は包含し多く間隐充買をしている。交代は岩体の周縁部に著し く初期は譬聞に治い交代されていた鉣物も遂には光学力位を同じくする小さい粒状晶り 散点になる。この交代が著しいと石英は玟状変晶質となるが，又脈状の事も多い。

欧鉄輝石 力り長石の比較的少小岩体の内部にのみ含まれアルカリ花崗岩㰓岩には虎

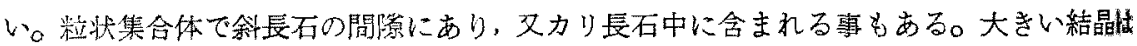
粒状䣄長石を含み poikiloblastic texture を示す事もある。淡葓緑色で多色性は極めて 弱く $2 \mathrm{~V}(+)=62^{\circ} \sim 67^{\circ}, \beta=1.727 \mathrm{c} \wedge Z=48^{\circ} \sim 49^{\circ}$ 。周縁部には角閃石及黑雲母伴引。

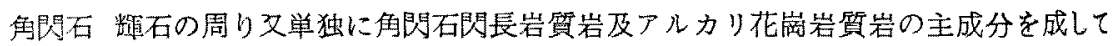

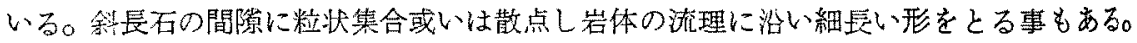
其他 poikiloblastic になる事, 粒状及細脈を成す事もある。 $2 \mathrm{~V}(-)=37 \sim 42^{\circ}, \mathrm{c} \wedge \mathrm{Z}=$ $20 \sim 22^{\circ}{ }_{1}(110)=1.679, \mu_{2}(110)=1.701, \mathrm{X}=$ pale greenish yellow, $\mathrm{Y}=$ yellowish green, $Z=$ bluish greer greenish blue

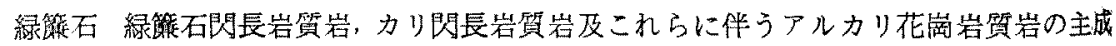
分として，页角畞閃長岩質岩の副成分として含まれる。斜長石の間㩐或はカリ長石，石英中

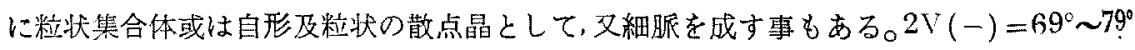

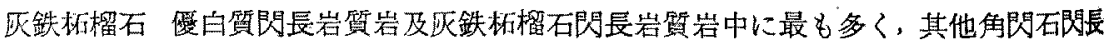

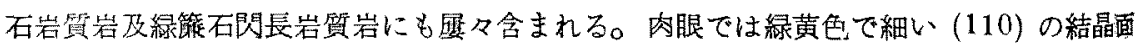
が良く発㙂している。鏡下では淡黄色で䣄長石の間隙及石英中に自形晶或は粒状集合体 戍している。可成り著しい複屈折があり又累带棈造を呈し polysynthetic twinn が愽 達している。 $\mathrm{N}>1.818, \mathrm{a}_{0}=11.99 \sim 12.00 \AA^{31}$

[未完]

1) 杉健一，久網正典；岩鋪 31，209，1944

2) Battey, M. H.; Geol. Mag. 92, 104, 1955

3) X線粉末写真撮影解析さ九州大学広渡文利氏によるもので，氏に対し愿く感謝する 